\title{
Presentación. Diversidad e interculturalidad: la comunicación como estrategia Mirar a los otros para volver a mirarnos o la idea de la interculturalidad como medio y no fin
}

¿En qué estadio de la globalización/mundialización navegamos hoy? ¿Qué implicancias tiene en la perspectiva del derecho, de la comunicación, la diversidad y la justicia como un derecho? El dossier que se despliega en este número da cuenta de interrogantes que permiten suponer una mirada crítica sobre estos procesos situados en la modernización y, por tanto, en contextos políticos, sociales, económicos y culturales complejos y más vinculados a las interrogantes que a las certezas. Se invita, en consecuencia, a pensar estos procesos desde la crítica, es decir, a pensar los artículos que siguen desde la crítica que avanza a contrapelo de la naturalización, aquella que interpela a conceptos como la "multiculturalidad" e intenta ubicarse en un lugar discursivo de mayor impacto que aquel destinado a la perfomance de modas académicas y mediáticas.

La propuesta, entonces, es concebir a los tejidos sociales y culturales como en permanente elaboración, en donde los sistemas simbólicos están subordinados a condiciones de dominancia, cuando el poder forma parte de la propia matriz que determina el tejido. No desconociendo lo anterior, la comunicación es interacción que deviene en predominios diversos, desde lo residual, lo dominante y lo emergente dentro de sistemas que no son inocuos. En eso, lo intercultural se traduce como la tensión no resuelta, aquella fórmula de interacción que permite mirar al otro, habitando al otro y sabiendo que el otro también habita a quien lo mira. Y es ahí donde el mirar es un lenguaje atrevido, porque implica una voluntad de encuentro o una voluntad de fractura. ¿Qué acciones, qué políticas, que estructuras van prefigurando los fragmentos de este viaje de encuentros, qué se tensiona, qué poderes se desdibujan desde la cotidianeidad en donde se producen los discursos bajo regímenes comunicacionales y mediáticos ya situados en un modelo de producción occidental que aparece aún inquebrantable a nivel material y simbólico?

Las estrategias vinculadas a operar bajos sistemas de influencias se encuentran en el artículo Emergencia indígena mass mediática: acción colectiva de autorrepresentación social y legitimación, en donde se valora -en la perspectiva de la década final del siglo XX y la inaugural del siglo XXI- la rearticulación del movimiento indígena en América Latina. El énfasis aquí está dado sobre el ciberactivismo, en tanto las estrategias comunicacionales que levanta buscarían "generar una autorepresentación social que refute los históricos discursos discriminatorios de la sociedad mayoritaria y la tergiversación que los medios de comunicación masivos les han impuesto a los indígenas, además de buscar y legitimar sus demandas actuales". Se cuestiona así la hegemonía monoétnica, buscando una pulsión 
renovada sobre la pertinencia de las matrices occidentales como dominantes, cuando se podría sugerir mayor presencia y eficacia de acción en las fisuras dramáticas que finalmente constituyen el actual estadio de desarrollo de la mundialización. La etnicidad, por tanto, requiere y supervive en acciones comunicativas, logrando cuestionar aquí el concepto de ciudadanía esgrimido desde la concepción moderna/actual/liberal de Estado-nación. Relevante es que en este texto se valore que la "importancia de contar y ejercer su derecho a comunicar -en el caso particular de las poblaciones indígenas- está en la posibilidad de dar su batalla a nivel discursivo, entrando a la disputa de la formación de significados, a expresar sus simbolizaciones a través de la difusión mass mediática” entre otras acciones que exponen al poder que las condiciona.

Es así como estos ensayos, en donde se rescatan -en su mayoría- resultados preliminares de investigaciones, confieren sentido en la línea de Memoria, Identidad e Interculturalidad desarrollada al interior del Centro de Estudios de la Comunicación (Cecom) del Instituto de la Comunicación e Imagen de la Universidad de Chile. Ensayos que condensan y sugieren análisis críticos más intensos a los procesos inacabados de construcciones nacionales, identitarias, en donde el peso de las estructuras sociales (clases y sus disposiciones simbólicas) sigue siendo clave a la hora de acoger/enfrentar la idea de los otros.

\section{Ximena Póo Figueroa \\ Universidad de Chile}

